\title{
Study of untreated hypertensive subjects by means of continuous intra-arterial blood pressure recordings
}

\author{
A. D. GOLDBERG, E. B. RAFTERY, P. M. M. CASHMAN, \\ AND F. D. STOTT \\ From the Cardiology Department and Bio-engineering Division, Northwick Park Hospital and Clinical \\ Research Centre, Harrow, Middlesex
}

SUMMARY Continuous recording of intra-arterial blood pressure and electrocardiograms has been performed in 41 ambulant untreated essential hypertensive subjects for periods up to 48 hours. Statistical analysis of the results has revealed: (1) A group of patients who developed a persistent tachycardia during the day. This response was not observed in a control population free of overt cardiovascular disease. (2) Three different haemodynamic responses to day-time activities suggesting different mechanisms for the production of high blood pressures. No normal controls are available for these changes. (3) No differences in responses between patients defined as 'labile' and 'fixed' hypertensives.

Continuous recording of intra-arterial blood pressure in unrestrained subjects is technically difficult but is fundamental to the understanding of blood pressure control and mechanisms of hypertension. The development of the Oxford continuous recorder in the Department of the Regius Professor of Physic at Oxford University has made it possible to study blood pressure and electrocardiographic abnormalities over long periods with a high degree of accuracy (Bevan et al., 1969).

We have used a refined version of this instrument (Goldberg et al., 1976) to record the blood pressure of untreated hypertensive subjects over a 24-hour period, and have used computer analysis of the data to characterise the blood pressure and heart rate in a quantitative manner.

\section{Subjects}

Studies were performed on 41 untreated hypertensive patients recruited from the Harrow Hypertension Clinic. There were 29 men and 12 women ranging in age from 23 years to 66 years (mean 47 years). Clinical details are given in Table 1 . Clinic blood pressures are the mean of the recordings made at the 3 clinic visits before the study. A Hawksley random zero instrument was used to record systolic (phase I) and diastolic (phase IV) pressures after 5 minutes resting supine and 1 Received for publication 27 April 1977 minute standing. Patients were considered 'hypertensive' when their mean supine blood pressure was above $145 \mathrm{mmHg}$ systolic or above $95 \mathrm{mmHg}$ diastolic. All studies were performed with the object of observing the effects of pharmacological interventions and informed consent was obtained from each patient. The procedures for these studies were approved by the Hospital Ethical Committee (E 252). The analysis of the first 24 hours of each continuous recording without any drug treatment provided the data for this report.

Twenty-six studies were performed on fully ambulant in-patients and 15 on out-patients attending the clinic in the early morning and evening and spending the rest of the day in their normal occupation and the night at home. Those sent home were younger than those investigated as in-patients and had lower clinic blood pressures (Table 2).

All subjects were asked to record the time of activities in the form of a diary.

\section{Methods}

The methods used and the evaluation of the equipment have been fully described elsewhere (Goldberg et al., 1976). Each patient reported to the hospital at 0900 on the study day. A cannula was inserted percutaneously into the left brachial artery, and the recording apparatus was attached. The patients were then observed for 2 hours and the pulses were 
palpated at frequent intervals. They were not allowed to leave the ward area until the observers were satisfied that the situation was stable and the recording satisfactory. They reported back at 12-hour intervals for servicing and calibration of the equipment.

The tape recordings were replayed on an Oxford Instruments tape deck with a continuous paper write-out at $0.04 \mathrm{~mm} / \mathrm{s}$ and the facility for write-out up to $40 \mathrm{~mm} / \mathrm{s}$ for more detailed wave-form analysis. A computer was used to read the peaks and troughs of each pressure pulse and also the time between successive troughs and store this information in incidence histogram form. The histograms were produced at the end of each timed analysis and a statistical programme used to produce the mean and variance of each parameter. Consequently, for analysis of any part of a 24-hour period

Table 1 Clinical features of patients in this study

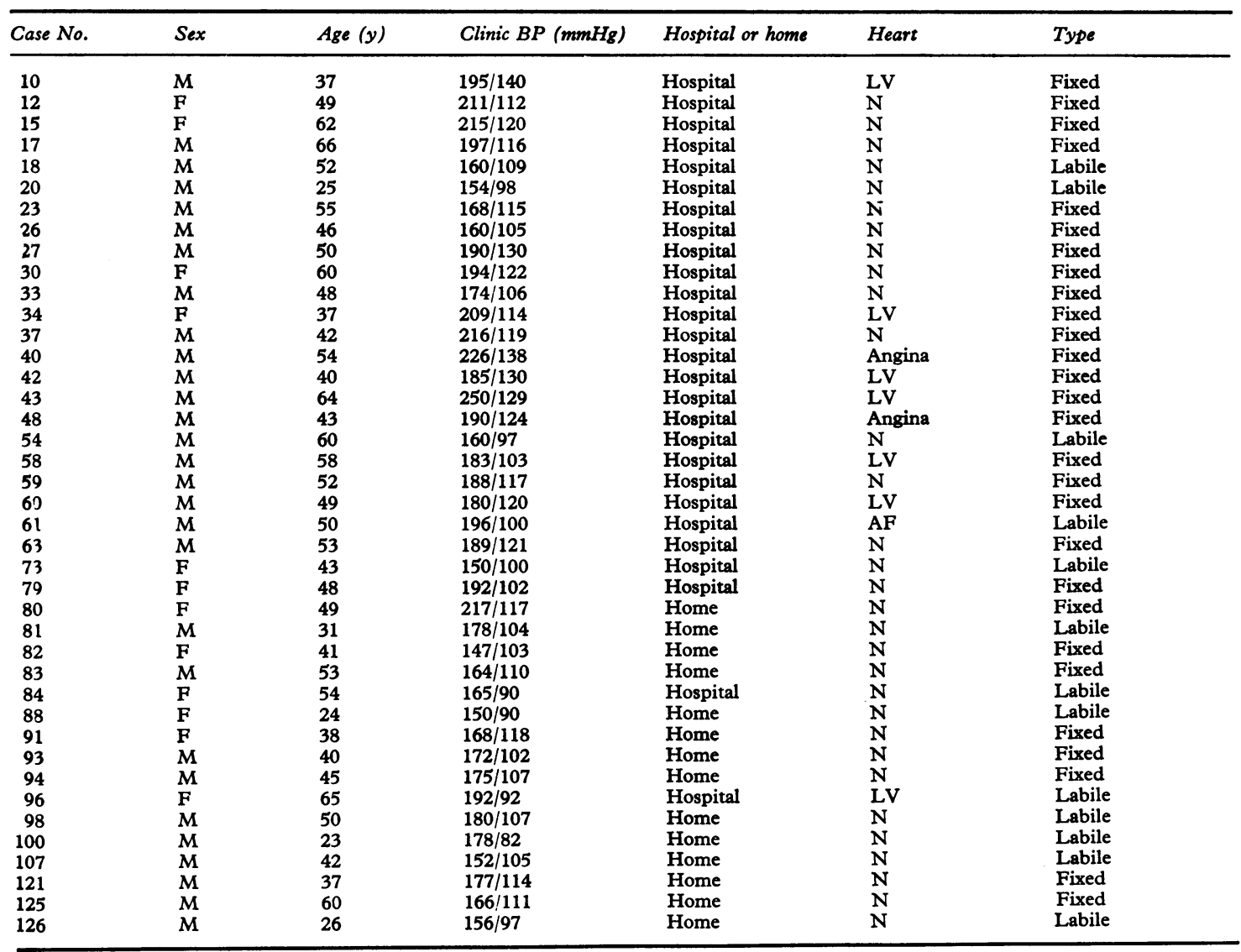

Clinic blood pressure $=$ mean of supine and standing blood pressures at three clinic visits before investigation; labile $=$ diastolic blood pressure recorded at below $90 \mathrm{mmHg}$ on at least one occasion before treatment (Eich et al., 1962); fixed = diastolic blood pressure never recorded below $90 \mathrm{mmHg}$ before treatment; $\mathrm{LV}=$ electrocardiographic evidence of ischaemic heart disease or left ventricular hypertrophy; $\mathrm{AF}=$ atrial fibrillation; $\mathrm{N}=$ no clinical cvidence of cardiac disease.

Table 2 Comparison of patients investigated in hospital with those investigated at home

\begin{tabular}{|c|c|c|c|c|}
\hline & & Hospital & Home & Significance \\
\hline $\begin{array}{l}\text { Age: } \\
\text { Systolic pressure: } \\
\text { Diastolic pressure: }\end{array}$ & $\begin{array}{l}\text { mean }(S D) \text { y } \\
\text { mean }(S D) \text { mmHg } \\
\text { mean (SD) mmHg }\end{array}$ & $\begin{array}{c}50 \cdot 8(+9 \cdot 7) \\
190 \cdot 6(+22 \cdot 5) \\
114 \cdot 6(+14 \cdot 1)\end{array}$ & $\begin{array}{r}40 \cdot 1(+11 \cdot 1) \\
169 \cdot 5(+18 \cdot 2) \\
104 \cdot 1(+10 \cdot 0)\end{array}$ & $\begin{array}{l}P<0.01 \\
P<0.01 \\
P<0.05\end{array}$ \\
\hline
\end{tabular}


a histogram and mean and variance data were produced for systolic pressure, diastolic pressure, and pulse interval time.

From the continuous write-outs (Fig. 1), it was seen that the 24 hours could be divided into two very distinct periods: that of sleep and that of daytime activities. These were separated by a variable length of time in the evening when pressures and rates were gradually falling because of lack of activity. For this reason each tape was studied in 2 distinct parts: the period between about 0100 and 0600 when it was known from the patient's diary that he was asleep and the qualitative record showed loss of variability and quiescence, and daytime between 0900 and 1900 when the patient was active either as an in-patient or an out-patient.
For a characterisation of each subject during the day it was necessary to minimise the effect of brief variations induced by physiological processes such as exercise, feeding, sitting still, smoking, etc. It was found that a random hour analysed in consecutive 2-minute periods contained great variation in pressures and heart rates. By progressive reduction of the resolution to a 3-hour analysis, these effects could all be balanced and little variation was found in daytime pressures and heart rates between consecutive 3-hour periods or 3-hour periods on successive days (Table 3 ). It was, therefore, decided to characterise each patient's daytime pressures and rates numerically by analysing a single 3-hour period of the day between 0900 and 1900 after assessing the paper chart recording to
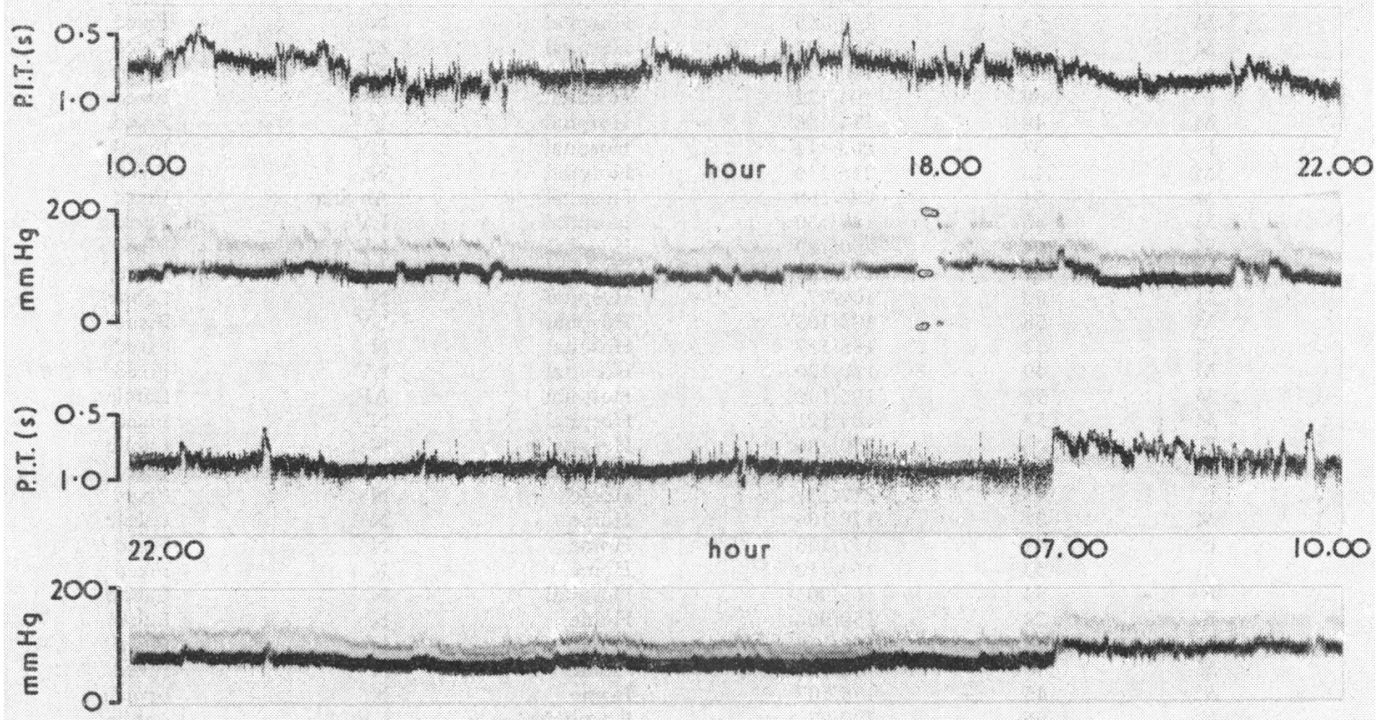

Fig. 1 Continuous recording of blood pressure and heart rate (PIT, pulse interval time) in a single patient. Note the fall of pressure with sleep (2200) and the smart rise on awakening (0700).

Table 3 Comparison of 3-hour mean values on consecutive days

\begin{tabular}{|c|c|c|c|c|c|c|}
\hline \multirow[b]{2}{*}{ Case No. } & \multicolumn{2}{|c|}{ Mean systolic pressure $(\mathrm{mmHg})$} & \multicolumn{2}{|c|}{ Mean diastolic pressure $(\mathrm{mmHg})$} & \multicolumn{2}{|c|}{ Mean rate/min } \\
\hline & Day 1 & Day 2 & Day 1 & Day 2 & Day 1 & Day 2 \\
\hline 37 & 190 & 190 & 114 & 110 & 81 & 85 \\
\hline 91 & 148 & 138 & 94 & 88 & 85 & 76 \\
\hline 93 & 154 & 158 & 106 & 106 & 106 & 109 \\
\hline 94 & 156 & 154 & 96 & 96 & 86 & 79 \\
\hline 96 & 166 & 170 & 88 & 88 & 73 & 75 \\
\hline 121 & 170 & 172 & 114 & 124 & 120 & 124 \\
\hline 125 & 176 & 172 & 104 & 110 & 77 & 83 \\
\hline 126 & 134 & 136 & 88 & 88 & 125 & 120 \\
\hline
\end{tabular}


ensure that the quality of recording was satisfactory. A 3-hour sample selected from the period between 0100 and 0600 was analysed to characterise the night-time.

\section{Results}

The blood pressure and electrocardiogram were of sufficient quality for analysis of the daytime period in 41 and the night-time period in 34 studies.

\section{ELECTROCARDIOGRAM}

Arrhythmias were seen in 4 patients. One was in atrial fibrillation throughout the study. Another patient had frequent extrasystoles and 2 patients had frequent ventricular extrasystoles. Isolated atrial and ventricular extrasystoles (less than 10 per hour) were detected in 10 other patients.

\section{HEART RATE}

Mean heart rates during the day varied between $59^{\circ}$ beats per minute and 130 beats per minute (mean of population $93 \pm 19.0$ beats per minute).

Heart rates were higher in those investigated as out-patients (mean $=102 \cdot 1 \pm 20 \cdot 5$ per minute) than in-patients (mean $89.6 \pm 16.5$ beats per minute). It was possible to pair 8 subjects investigated at home with 8 investigated in hospital on the basis of age, sex, and clinic blood pressures (Table 4). There was no significant difference in daytime heart rates between the pairs. It was, therefore, considered that the mean heart rate was not affected by the method of study, but was a true reflection of each subject's physiological responses.

Table 4 Heart rates during the day in patients paired for age, sex, and clinic blood pressure

\begin{tabular}{llllll}
\hline Place & $\begin{array}{l}\text { Case } \\
\text { No. }\end{array}$ & Sex & $\begin{array}{c}\text { Age } \\
(y)\end{array}$ & Clinic BP & $\begin{array}{c}\text { Mean heart } \\
\text { rate day } \\
\text { (bpm) }\end{array}$ \\
\hline Hospital & 12 & F & 49 & $211 / 112$ & 130 \\
Home & 80 & F & 49 & $217 / 117$ & 130 \\
Hospital & 33 & M & 48 & $174 / 106$ & 81 \\
Home & 81 & M & 31 & $178 / 104$ & 81 \\
Hospital & 73 & F & 43 & $150 / 100$ & 83 \\
Home & 82 & F & 41 & $147 / 103$ & 103 \\
Hospital & 18 & M & 52 & $160 / 109$ & 83 \\
Home & 83 & M & 53 & $164 / 160$ & 120 \\
Hospital & 34 & F & 37 & $209 / 114$ & 74 \\
Home & 91 & F & 38 & $168 / 118$ & 77 \\
Hospital & 29 & M & 46 & $160 / 105$ & 97 \\
Home & 93 & M & 40 & $172 / 102$ & 106 \\
Hospital & 59 & M & 52 & $188 / 117$ & 108 \\
Home & 94 & M & 45 & $175 / 107$ & 86 \\
Hospital & 20 & M & 25 & $154 / 98$ & 88 \\
Home & 100 & M & 23 & $178 / 82$ & 91 \\
\hline
\end{tabular}

The distribution of mean daytime heart rates in these hypertensive patients is shown in the upper part of Fig. 2. This analysis showed a bimodal distribution, with 9 subjects having heart rates greater than 110 beats per minute.

The mean heart rates at night varied between 54 beats per minute and 94 beats per minute (mean for group $74.1 \pm 8.9$ beats per minute). The distribution curve, shown in the upper part of Fig. 3, was unimodal with a small scatter. In all but 3 patients the nocturnal rate was lower than the daytime. The mean difference was $19 \cdot 3 \pm 16.5$ beats per minute $(\mathrm{P}<0.01)$.

Eighteen patients showed a difference in mean heart rate between day and night of less than 20 beats per minute, and this group included 8 of the 9 with clinical evidence of cardiac damage $\left(\chi^{2}=12.0\right.$; $P<0.01$ ).

\section{BLOOD PRESSURE}

In all patients the blood pressure showed obvious variability. In the whole group the mean daytime systolic pressure varied from $124 \mathrm{mmHg}$ to 288 $\mathrm{mmHg}$ (mean for group $=170.0 \pm 23.0 \mathrm{mmHg}$ ) and the mean diastolic pressure varied from $74 \mathrm{mmHg}$ to $136 \mathrm{mmHg}$ (mean for group $=105.6 \pm 22.5$ $\mathrm{mmHg}$ ).

In all subjects the night-time systolic pressure and with one exception the diastolic pressure was lower than that during the day. The mean difference for the whole group was $35.5 \pm 14.0 \mathrm{mmHg}$ (systolic) and $22.4 \pm 12.3 \mathrm{mmHg}$ (diastolic).
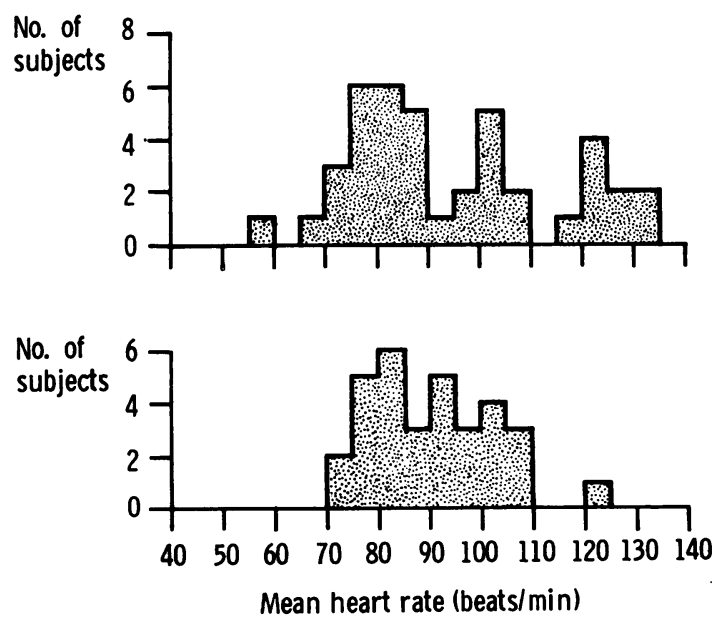

Fig. 2 Histograms showing the distribution of mean 3-hour daytime heart rates in this group of 'hypertensive' patients (top) and a control group of 'normal' subjects (Raftery and Cashman, 1976) (bottom). 
The mean night systolic pressure varied between $76 \mathrm{mmHg}$ and $168 \mathrm{mmHg}$ (mean for group $131 \cdot 7 \pm 24 \cdot 1 \mathrm{mmHg}$ ) and diastolic pressure between $50 \mathrm{mmHg}$ and $108 \mathrm{mmHg}$ (mean for group 79.4 \pm $15 \cdot 1 \mathrm{mmHg}$ ).

\section{ARTERIAL PRESSURE AND HEART RATE}

Inspection of the paper chart record showed that increases in pressure and heart rate over short periods of time were closely related. However, there was no correlation between mean heart rates and mean systolic and diastolic pressures in the whole group during the day or night (Fig. 4).

The changes produced in the heart rates and blood pressures by daytime activities were not consistent in the group (Fig. 5). However, when the nocturnal values for heart rates and pressures were taken as basal and the percentage changes in rates were compared with percentage change in pressures, a weak correlation could be shown (systolic $r=$ 0.437 ; $\mathrm{P}>0.01$; diastolic $\mathrm{r}=0.546, \quad \mathrm{P}<0.01$ ) (Fig. 6).

There was a suggestion of three separate groups, and this was seen more clearly when the data were expressed in histogram form (Fig. 7). In the centre was a group of subjects in whom the heart rate and systolic and diastolic pressures rose in proportion
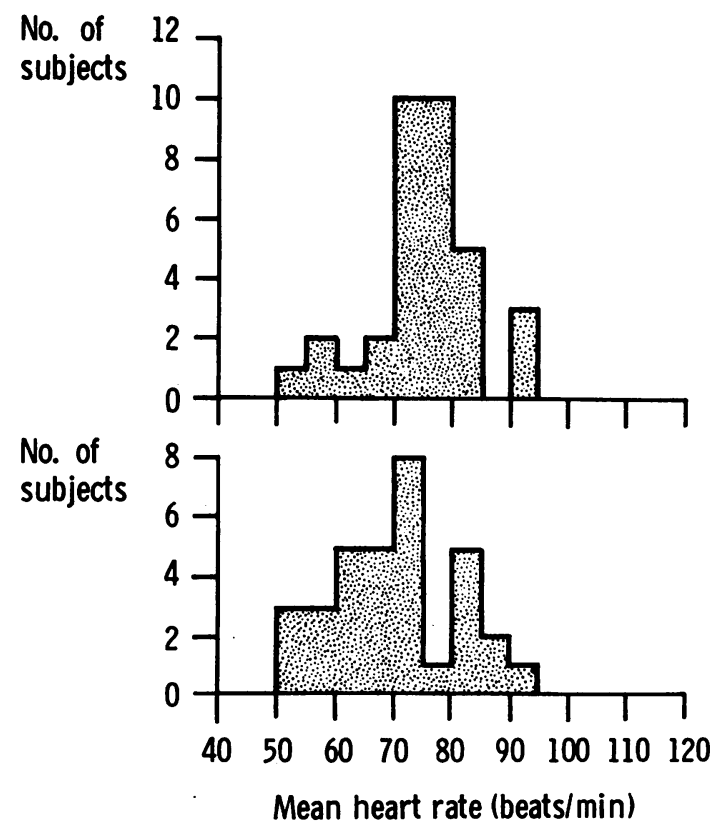

Fig. 3 Histogram for the mean 3-hour nocturnal heart rates in the same two populations. during the daytime activities (ratio 0.8 to 1.4 ). $\stackrel{\vec{c}}{\mathrm{c}}$ To the left of these was a group in whom the pressures increased more than the heart rates (ratio $0 \stackrel{9}{\rightarrow}$ to $0 \cdot 8$ ). To the right of the histogram was a third 0 group in whom the heart rates increased out of proportion to the pressures (ratio greater than 1.4).

\section{Discussion}

Three important findings emerge from this study.

(1) HEART RATES DURING DAY

Of the 41 untreated subjects, 9 had mean day heart rates greater than 110 beats per minute. Data $\overrightarrow{0}$ available from a heart rate study performed on $\dot{\sigma}$ carefully-defined 'normal' subjects (Raftery and of Cashman, 1976) was available for comparison (Fig. 2 and 3).

This showed a similar distribution of mean heart $\vec{C}$ rates during the night-time, but no comparable group of subjects with a relative tachycardia during $\Phi$ the day could be shown in the 'normal' population. $\vec{\oplus}$ This suggests that the development of daytime $\infty$ tachycardia in some hypertensive subjects is an abnormal response which may have diagnostic significance. The cause of this tachycardia was sought by comparing the two groups of hypertensives but they did not differ significantly in age, $\stackrel{\mathbb{D}}{\perp}$ sex ratio, lability, or level of clinic blood pressures, mean day systolic or diastolic pressures.

An increased heart rate in hypertensive patients has been noted in many laboratory studies. Eich et al. (1962) suggested that hypertensives first enter a labile period with increased heart rate and cardiac $\mathbb{\mathbb { N }}$ output which subsequently decreased to normal with a high peripheral resistance. On repeat in- $\frac{5}{3}$ vestigation 50 months later (Eich et al., 1966) this group showed a decrease towards normal levels with an increase in peripheral resistance, but some of the most dramatic changes were seen in patients 5 receiving treatment for hypertension.

Frohlich et al. (1970) compared the haemodynamics of normals and four different grades of $N$ hypertensives and showed an increase in heart rate $N$ in each group of hypertensives over the normal $N$ population but no difference in rate according to $\frac{W}{\sigma}$ severity. However, they concluded that the high heart rate was only associated with the labile group. Further studies from Cleveland (Ibrahim et al., $\stackrel{\Phi}{+}$ 1975) now suggest that there is a separate group of $?$ hypertensives with established high cardiac output ${ }^{\circ}$ and high heart rate without progression to normal $\overrightarrow{\mathbb{D}}$ cardiac output. Julius and Conway (1968) in a $\frac{\rho}{\mathbb{D}}$ comparison of haemodynamics at rest and during $\frac{\varrho}{\sigma}$ exercise could show a difference in heart rate between the normals and borderline hypertensives o 
in a group under 35 years of age only at rest and on extreme exercise. Lund-Johansen (1967) also showed an increased heart rate in young early hypertensives compared with normals, 21 of the 93 patients having a resting heart rate greater than the highest normal. At all levels of exercise this greater heart rate was maintained.

We can confirm suggestions from the laboratory studies of a higher mean heart rate in some hypertensives, but no association was found between age or level of blood pressure, thus making it more likely that this is a separate group rather than part of a progression in the disease. The cause of the high heart rate has been the subject of much speculation. Since the role of noradrenaline secretion in hypertension resulting from phaeochromcytoma was established (von Euler et al., 1954) many workers have measured catecholamine levels in essential hypertension as an index of sympathetic activity. Resting diastolic blood pressure has been correlated with plasma noradrenaline (Louis et al., 1973) and plasma dopamine $\beta$ hydroxylase (Geffen et al., 1973), while an increase in plasma levels of catecholamines at rest has been shown by Engelman et al. (1970).

However, the evidence for increased urinary excretion of catecholamines in essential hypertension is not so convincing. DeQuattro and Chan (1972) reported increased excretion of noradrenaline and Cuche et al. (1975) of homovanillic acid but not noradrenaline. Lorimer et al. (1971), Nestel (1969), Nestel and Esler (1970), and Esler and Nestel (1973) have shown no difference in catecholamine excretion between normals and hypertensives at rest, though there is a greater response in hypertensives than normals during stress of various types.

The role of the sympathetic system in essential hypertension has been questioned by Korner et al. (1973) who studied the effects of total autonomic blockade by atropine and $\beta$-blocking drugs, and total peripheral blockade with guanethadine and phentolamine. While the cardiac slowing effect of $\beta$-blockade was similar in normotensives and hypertensives the increase in heart rate with

DAYTIME

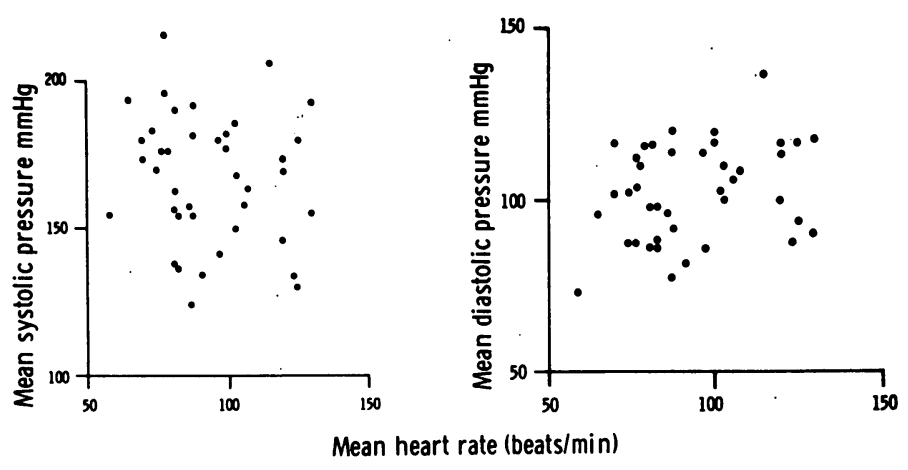

Fig. 4 Plots of mean 3-hour systolic and diastolic blood pressures against mean 3-hour heart rates by day and by night. There is clearly no meaningful correlation to be seen.

NIGHT TIME

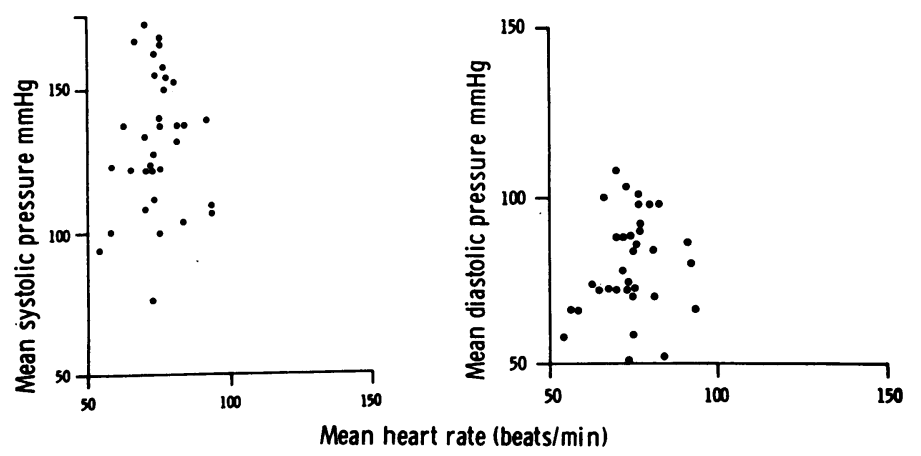


atropine was significantly less in hypertensives, thus suggesting a lower initial vagal tone. This might explain the decreased baroreceptor activity reported in hypertensives by Bristow et al. (1969), Gribbin et al. (1971), and Takeshita et al. (1975).

Another possibility is that the high heart rate may be the result of increased sensitivity of the heart to normal levels of catecholamines, perhaps because of lack of vagal tone. Thus, George et al. (1972) showed a significant intersubject heart rate response to infusion of isoprenaline, but similarity in response by a single subject tested repeatedly.

The nocturnal heart rates in this study were similar in the hypertensive patients and normo-
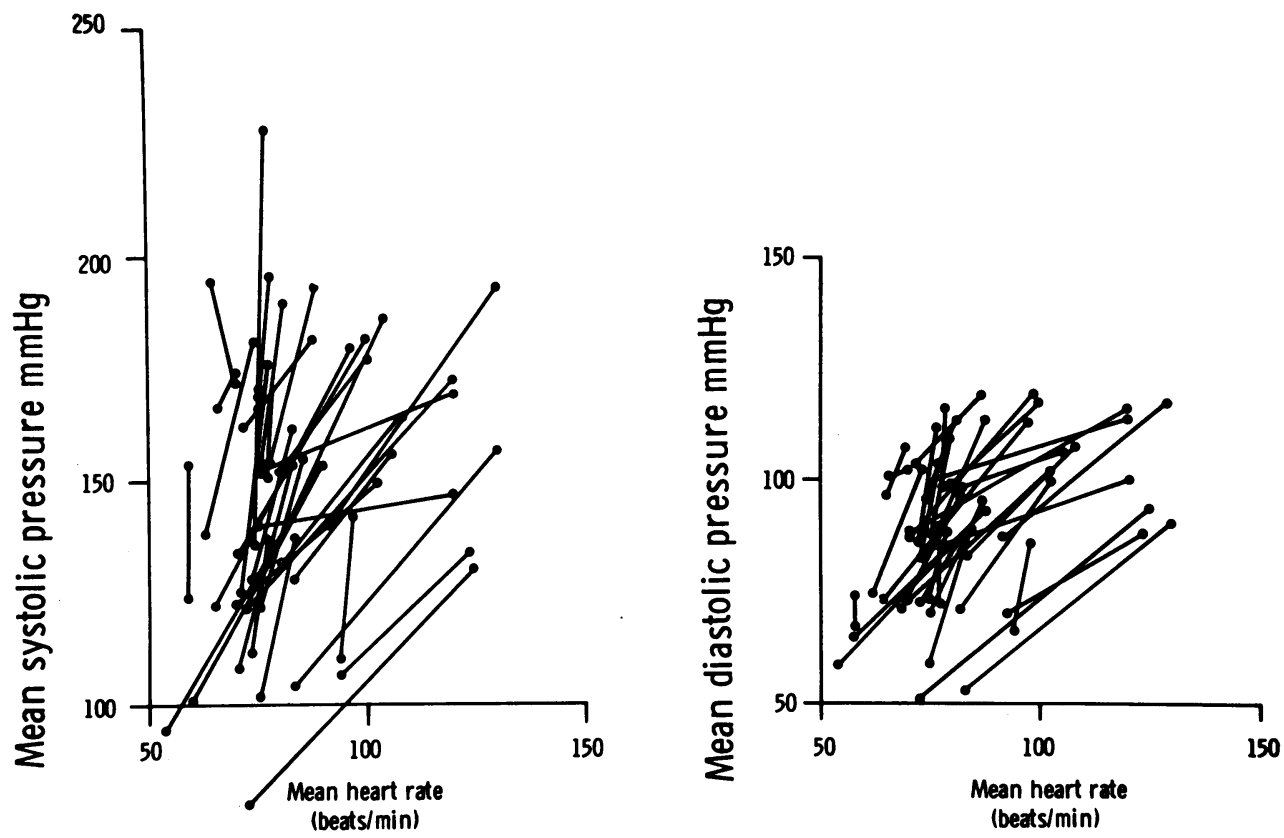

Fig. 5 Plots of mean nocturnal and daytime pressures against mean nocturnal and daytime heart rates. In most instances, daytime pressures and rates increase but in some cases the pressure rises while the rate changes very little, and in others the rate increases with very little change in pressure.
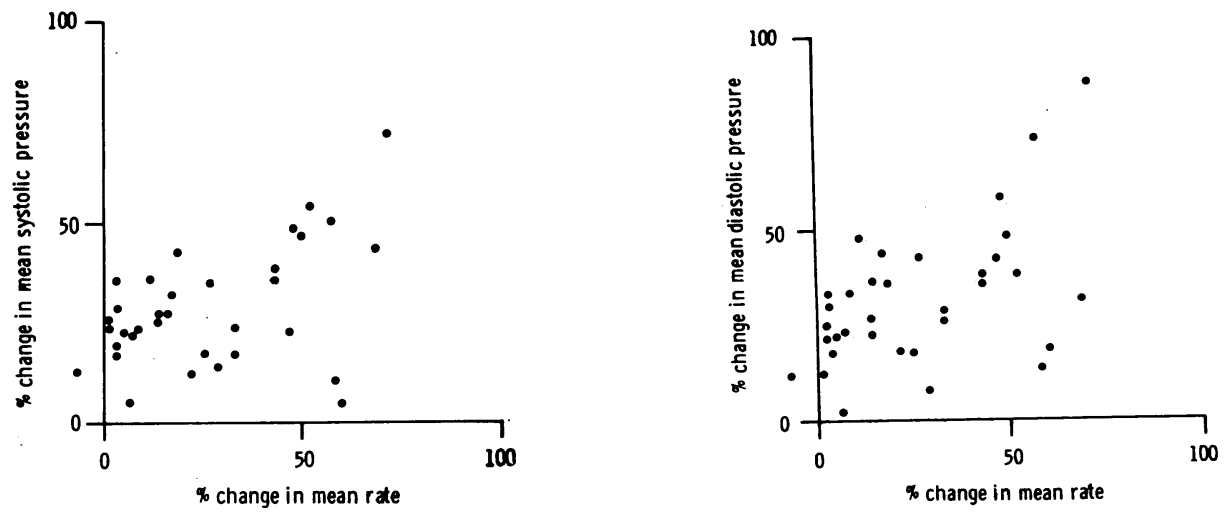

Fig. 6 The same data as Fig. 5 'normalised' expressing the changes as percentages. There is a weak correlation between the pressure changes and heart rate changes, but the suggestion of 3 separate groups has now appeared. 
tensive control population. This confirms that the increase in heart rate is the result of an extracardiac cause which if found may be the cause of hypertension in this group.

\section{(2) RATE AND PRESSURE CHANGES}

During sleep the heart rate and/or blood pressure was lower than during the day, thus confirming previous reports (Smirk, 1973; Bristow et al., 1969; Khatri and Freis, 1969; Richardson et al., 1964; Schneider and Costiloe, 1975). From inspection of the paper chart records it was seen that during the day the heart rate and arterial pressures increased proportionately in response to short stimuli. However, no obvious correlation could be found between the computed mean daytime pressures and heart rates. Since the computed nocturnal heart rates were similar to those found in the normal population study of Raftery and Cashman (1976), it was decided to attempt to 'normalise' the group data by regarding the computed mean nocturnal heart rates and pressures as basal, and expressing the daytime means as percentage changes. When this was done, it was expected that there would be good positive correlation between the increase of mean heart rate and the increase in
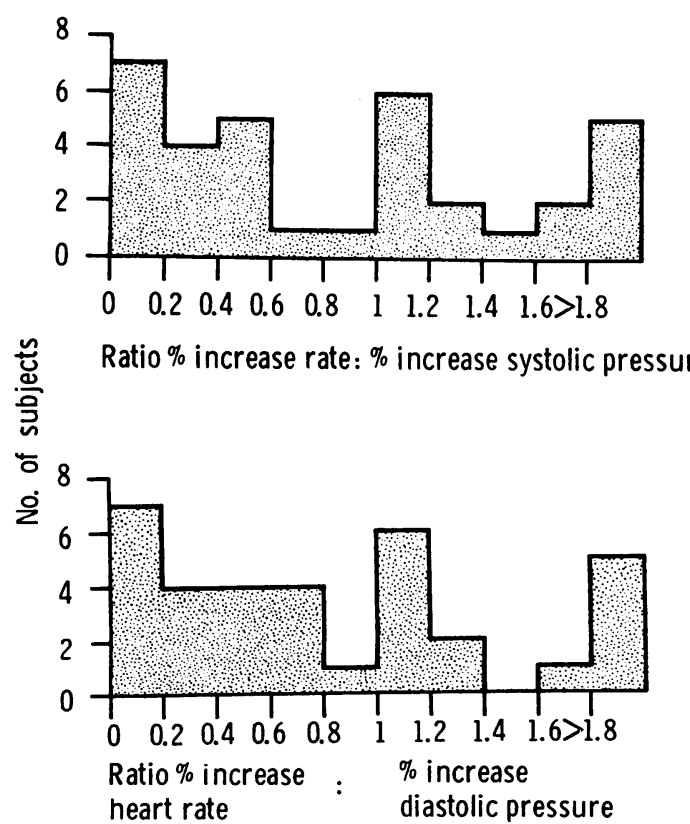

Fig. 7 The same data as Fig. 6 expressed as an incidence histogram. The 3 groups with different mechanisms of change are revealed. mean arterial blood pressures, but this relation was observed in only 9 patients.

The blood pressure responses of a normal population have not been studied, but it would be reasonable to assume that the physiological responses to the increasing cardiovascular demands of the day would be an increase in cardiac output and a varying vascular resistance to ensure flow to organs in need. The cardiac output is increased both by heart rate and stroke output changes. If total peripheral resistance remained unchanged this would be reflected in a proportional rise in rate and pressures in a central artery. The group of subjects in which this occurred may represent normal physiological changes, but at the upper end of a Gaussian distribution curve, perhaps because of blood volume increase.

We also found a group of patients who increased their arterial pressures without a proportional increase in heart rate. These were responding to the increased demands of the day by increasing stroke output and/or total peripheral resistance. Of the 9 patients in this series who had clinical evidence of myocardial damage, 8 were in this group. None had tachycardia or other overt evidence of left ventricular failure, and the precise significance of this observation is not clear. However, we have observed a similar fixity in heart rate responses in other patients with ischaemic heart disease, and it may be that this finding is related to ischaemia rather than to hypertension. At the opposite end of the spectrum were patients whose heart rates increased out of proportion to arterial blood pressures and these must have been responding by increasing cardiac output but retaining or decreasing total peripheral resistance.

While it has not been possible with this small number of subjects investigated to produce three separate groups of subjects, empirical grouping did not reveal any other systematic or clinical differences; in particular there was no difference in age, clinic blood pressures, daytime or night-time blood pressures, or night heart rates.

An increase in pressure in a closed expansile system, can have only 3 possible mechanisms-the resistance past the site of measurement, or the flow through the system, or the volume of fluid contained, must increase. By comparing the increase in values between the night and day it appears that the three mechanisms may be separated and this may help in selecting the appropriate therapy for the individual subject.

(3) VARIABILITY OF PRESSURES

By examination of the paper chart record and from the analysis of variance of pressures it was not 
possible to separate the patients into labile and fixed groups.

Eich et al. (1962, 1966), Julius and Conway (1968), and Frohlich et al. (1970) have separated hypertensives into those with established high pressures and those in whom the diastolic pressure has been recorded above and below $90 \mathrm{mmHg}$ on different occasions ('labile' or 'borderline' hypertensives). A similar group of 13 patients who answered to this description was identified in this series and compared with the remaining 28 . As in the reported series, the labile hypertensives were younger (means 42 years and 49 years) and had lower mean day pressures. However, the heart rates during the day and night were identical in the two groups, unlike the previous studies in which the labile hypertensives had a higher mean heart rate than the fixed. This could be explained by the difference between a laboratory investigation and our continuous method of investigation. Those subjects with high initial pressures which gradually settle on repeated examination may be those who have had a nervous reaction to the laboratory investigation as shown by high cardiac output and lower peripheral resistance, but when away from the laboratory settle rapidly to a similar haemodynamic state as other subjects as indicated by the similar heart rates.

\section{References}

Bevan, A. T., Honour, A. J., and Stott, F. H. (1969). Direct arterial pressure recording in unrestricted man. Clinical Science, 36, 329-344.

Bristow, J. D., Honour, A. J., Pickering, T. C., and Sleight, P. (1969). Cardiovascular and respiratory changes during sleep in normal and hypertensive subjects. Cardiovascular Research, 3, 476-485.

Cuche, J-L., Kuchel, O., Barbeau, A., and Genest, J. (1975). Urinary homovanillic acid, depamine and norepinephrine excretion in patients with essential hypertension. Fournal of the Canadian Medical Association, 112, 443-446.

DeQuattro, V., and Chan, S. (1972). Raised plasma catecholamines in some patients with primary hypertension. Lancet, 1, 806-809.

Eich, R. H., Peters, R. J., Cuddy, R. P., Smulyan. H., and Lyons, R. H. (1962). The hemodynamics in labile hypertension. American Heart fournal, 63, 188-195.

Eich, R. H., Cuddy, R. P., Smulyan, H., and Lyons, R. H. (1966). Hemodynamics in labile hypertension: a followup study. Circulation, 34, 299-307.

Engelman, K., Portnoy, B., and Sjoerdsma, A. (1970). Plasma catecholamine concentrations in patients with hypertension. Circulation Research, 26-27, Suppl. I, 141-145.

Esler, M. D., and Nestel, P. J. (1973). Sympathetic responsiveness to head-up tilt in essential hypertension. Clinical Science, 44, 213-226.

Frohlich, E. D., Kozul, V. J., Tarazi, R. C., and Dustan, H. P. (1970). Physiological comparison of labile and essential hypertension. Circulation Research, 26-27, Suppl. I, 55-63.
Geffen, L. B., Rush, R. A., Louis, W. J., and Doyle, A. E. (1973). Plasma dopamine $\beta$-hydroxylase and nor-adrenaline amounts in essential hypertension. Clinical Science, 44, $617-620$.

George, C. F., Conolly, M. E., Fenyveski, T., Briant, R., and Dollery, C. T. (1972). Intra-venously administered isoproterenol sulfate. Dose-response curves in man. Archives of Internal Medicine, 130, 361-364.

Goldberg, A. D., Raftery, E. B., and Green, H. L. (1976). The Oxford continuous blood-pressure recorder. Postgraduate Medical fournal, 52, Suppl. 7, 104-109.

Gribbin, B., Pickering, T. G., Sleight, P., and Peto, R. (1971). Effect of age and high blood pressure on baroreceptor sensitivity in man. Circulation Research, 29, 424-431.

Ibrahim, M. M., Tarazi, R. L., Dustan, H. P., Bravo, E. L., and Gifford, R. W. (1975). Hyperkinetic heart in severe hypertension. A separate clinical hemodynamic entity. American Fournal of Cardiology, 35, 667-674.

Julius, S., and Conway, J. (1968). Hemodynamic studies in patients with borderline blood pressure elevation. Circulation, 38, 282-288.

Khatri, I. M., and Freis, E. D. (1969). Hemodynamics changes during sleep in hypertensive patients. Circulation, 39, 785-790.

Korner, P. I., Shaw, J., Uther, J. B., West, M. J., McRitchie, R. J., and Richards, J. G. (1973). Autonomic and nonautonomic circulatory components in essential hypertension in man. Circulation, 48, 107-117.

Lorimer, A. R., Macfarlane, P. W., Provan, G., Duffy, T., and Lawrie, T. D. V. (1971). Blood pressure and catecholamine responses to 'stress' in normotensive and hypertensive subjects. Cardiovascular Research, 5, 169-173.

Louis, W. J., Doyle, A. E., and Anavekar, S. (1973). Plasma nor-epinephrine levels in essential hypertension. New England fournal of Medicine, 288, 599-601.

Lund-Johansen, P. (1967). Hemodynamics in early essential hypertension. Acta Medica Scandinavica, Suppl. 482.

Nestel, P. J. (1969). Blood pressure and catecholamine excretion after mental stress in labile hypertension. Lancet, 1, 692-694.

Nestel, P. J., and Esler, M. D. (1970). Patterns of catecholamine excretion in urine in hypertension. Circulation Research, 26-27, Suppl. II, 75-81.

Raftery, E. B., and Cashman, P. M. M. (1976). Long-term recording of the ECG in a normal population. Postgraduate Medical fournal, 52, Suppl. 7, 32-37.

Richardson, D. W., Honour, A. J., Fenton, G. W., Stott, F. H., and Pickering, G. W. (1964). Variation in arterial pressure throughout the day and night. Clinical Science, 26, 445-460.

Schneider, R. A., and Costiloe, J. P. (1975). Twenty-four $\frac{7}{2}$ hour automatic monitoring of blood pressure and heart rate at work and at home. American Heart fournal, 90, 695-702. N

Smirk, F. H. (1973). Casual, basal and supplemental blood pressure. In Hypertension, Mechanisms and Management, $\mathcal{O}$ p. 13. Ed. by G. Onesti, K. E. Kim, and J. H. Moyer. N Grune and Stratton, New York.

Takeshita, A., Tanaka, S., Kuroiwa, A., and Nakamura, M. (1975). Reduced baroreceptor sensitivity in borderline hypertension. Circulation, 51, 738-742.

von Euler, U. S., Hellner, S., and Purkhold (1954). Excretion $\stackrel{\mathscr{D}}{+}$ of nor-adrenaline in urine in hypertension. Scandinavian fournal of Clinical and Laboratory Investigation, 6, 54-59.

Requests for reprints to Dr E. B. Raftery, North- $\frac{\mathbb{Q}}{0}$ wick Park Hospital and Clinical Research Centre, Watford Road, Harrow, Middlesex HA1 3UJ. 